\title{
Die Probleem van die Lyde
}

Dit is 'n gangbare uitdrukking: ,die probleem van die lydę ' Bedoel word dan meestal die lyde van die gelowiges. So vat ook ons dit op. Lesers wat die Bybel ken, bring graag hierdie uitdrukking terstond in verband met die boek Job. In die boek Job word immers die probleem van die lyde van die gelowiges behandel. Hierdie gedagte is vry alge- 
meen. In die versoek van die redaksie om 'n artikel oor die probleem van die lydeo was ook opgesluit die gedagte dat ek sou skryf oor die boek Job.

Oor die boek Job wil ek graag 'n paar bladsye skryf. Maar tegelyk kom daarmee die vraag aan die orde of dit dan ook vanselfsprekend oor die probleem van die lyde en of dit hoofsaaklik daaroor moet gaan.

Dat die uitdrukking: "die probleem van die lyde" $\#$ mense terstond aan die boek Job laat dink, is verklaarbaar. Vele skrywers oor die boek Job het hierdie gedagte geuit. Ek noem o.a. die veelgebruikte boek van Bakker') en die, elk in eie kring, invloedryke werke van Aalders') en Vriezen"). In die laaste tyd egter het sommige beswaar gemaak teen die opvatting dat die boek Job 'n probleem behandel. Hulle beswaar geld nie alleen hulle wat hier die probleem van die lyde „,behandel" sien nie. Daar is ook geleerdes wat aan een of ander a n d e r probleem dink. Die jongste opvattinge wil van 'n p r o b l e e m nie weet nie. 'n Probleem, so sê hulle, is iets van die studeerkamer, is teologiese besinning, is iets van die verstand, van die denke. Maar van wat is die boek $\mathrm{J}_{\mathrm{ob}}$ dan? Van die eksistensie! so lui die antwoord‘).

Hiermee hang nog 'n ander kwessie saam. As in die boek Job 'n probleem behandel word, dan kan hierdie boek 'n leergedig genoem word, 'n gedig omdat dit digterlik is, en vervolgens leengedig om sy inhoud. Dan moet hierdie boek gereken word tot die sg. wysheidsliteratuur (of chokmatiese literatuur) van die O.T. (met Prediker en Spreuke). Maar tot die bowegenoemde jongere opvattinge behoort ook dat die boek Job nie 'n leergddig is nie en dus ook nie goed sou inpas in die raam van die gewone wysheidsliteratuur nie ${ }^{3}$ ).

Uit bowèstaande blyk, dat die jongste meninge tweërlei verskuiwing in die beskouing van die boek Job veroorsaak het. Die eerste lê op die terrein van sy aard of karakter. Dit gaan in hierdie boek nie om vrae van die denke nie/maar van die syn, van die eksistensie. Deur hierdie verskuiwing sou dan die behandeling van die boek Job verlos word van die abstraktheid waarmee dit gewoonlik bespreek word en win aan konkreetheid. Die denke ,behandel" die lyde, die smarte, met redeneringe, met woorde. Maar die syn reageer daarop direk, met skree, met kla! En dit is wat ons in die boek Job, altans uit die mond van sy hoofpersoon Job self, hoor: klagte!

Hiermee kom ons dan vanself tot die tweede verskuiwing in die beskouing van die boek Job. Hierdie lê op die terrein van sy vorm. 
Dit sou nie 'n leergedig wees nie, maar 'n klag. Job kla. Hy kla tot God. Die digter het nie 'n leer/maar 'n klag geskrywe ${ }^{6}$ ). Die klag is dan een van die vele "soorte" van literatuur (Gattungen"soos Lne Gunkel dit noem) wat ons in die Bybel aantref: liedere,"verhale, wette, profesif́ ens.

Hierdie verskuiwings sal wel veroorsaak wees deur invloede op wysgerige gebied van die eksistensialisme (by die eersgenoemde verskuiwing) en op die gebied van die Oud-festamentiese wetenskap van die literêr-historiese skool (by die tweede verskuiwing). Met hierdie opmerking bedoel ek geen etiketplakkery en ook nie dat die jongste opvattinge as onaanvaarbaar opsy gesit moet word nie. Nee, dergelike gesigspunte kan ons vir verstarring in die eksegese behoed. Tog moet ons hierdie opvattinge nie oordryf nie; seker nie daarvan 'n sisteem $<$ maak, waarin nou heel die Qu Testament/moet ingedwing/word nie. Dis seker waar dat Job kla. Maar/hy kla in digterlike woorde. Dit toon aan dat die boek Job tog 'n skrede verder van die eintlike lewe self F af staan as! bo yegenoemde opvatting ons wil laat glo. Die digterlike woorde-en dit word algemeen erken as in hoë mate digterlik, as die literêre hoogtepunt van die Ou Testament $t^{7}$ )-is tog nie gespreek deur ' $n$ man in lyde wat in die as sit nie (2:8). En ook die woorde van ander sprekers in hierdie boek, ook digterlik, is nie gespreek deur mense wat beurtelings lang redeneringe hou nie. Watter geselskap van vier, vyf man gesels nou in digvorm? Dis die werk van die digter, wie dit ook al mag wees. Dis hy wat die gedagtes van die persone wat optree, in hierdie skone vorm gegiet het. Ons het hier dan tog te doen met be we r k i $\mathbf{g}$ van iets uit die eksistensie, met besinning oor iets uit die lewe.

Die boek Job bevat trouens ook nie enkel klag nie. Job kla, maar die vriende redeneer en God vra, (My vra vas! (Foofst. 38-41).

Hulle wat spreek van 'n probleem, stem egter ook nie met mekaar ooreen wat ǵfetref die objek van die probleem nie, en dit wek die vraag op of hulle wel van die regte kant hierdie bybelboek probeer benader. Die een spreek van die probleem, ,de la rétribution divine et de la justice de Dieu") die ander van die probleem van die „Zelfrechtvaardiging" van God (Theodicee) ${ }^{\circ}$ ).

Ook wat die vorm, die letterkundige soort betref, is dear geen eenstemmigheid nie. Behalwe leerłdig en klag word ook genoem die dialoog, selfs die drama $^{10}$ ) of word as agtergrond die proses gesien ${ }^{11}$ ). 
Maar laat ons probeer self te sien wat ons van die boek Job moet dink en die vraag stel: is die lyde van die gelowige inderdaad 'n probleem en word die in die boek Job as probleem gestel én-dit mag 'n mens dan tog van 'n bybelboek verwag-o p g elos?

Ons antwoord is: nee!

Job is in groot lyde.

Is sy lyde 'n probleem?

Ons moet by die beantwoording van hierdie vraag onderskei tussen ons, lesers van die boek Job, en Job self. Daarom vra ons eers: is die lyde van Job vir óns 'n probleem? En dan moet ons erken: nee, want sy dyde word ons heeltemal verklaar in hoofstuk 1 en 2 . Ons weet waarom dit gaan:

Vervolgens vra ons: was sy lyde vir Job self 'n probleem? Nee! Aanvanklik ten minste nie. Dit het later 'n probleem vir hom geword. Ander mense het dit vir hom 'n probleem gemáák. Maar aanvanklik was dit nie die geval nie. As Job van alles, van kinders en goedere beroof is dan prys hy God: Die HERE het gegee en die HERE het geneem: die Naam van die HERE sy geloof! As sy toestand nog erger word deur sy bose swere en sy vrou hom aanspoor om dit te doen, wat die satan wou dat hy sou doen, God seën, dan sê hy: die goeie sou ons van God aanneem, en nie ook die slegte aanneem nie? Job staan nog op dieselfde standpunt as na die eerste beproewing. Sy woorde uit 2: 10 sluit aan by die uit $1: 21$. Dit is die praktiese toepassing daarvan. Wel merk ons op dat hy hom nou nie heeltemal só sterk uitdruk as die eerste keer nie. Hy spreek nou in die vorm van 'n vraag. Maar by dit alles het Job nie gesondig met sy lippe nie. „Met sy lippe” nie. Dis nie ' $n$ beperking, in die sin van: wel in sy hart. Dis 'n versterking in die sin van: met geen enkele woord nie. Later sondig Job wel met sy lippe! In sy spreke.

Ons konstateer dus dat in die begin van die boek Job van geen probleem sprake is, altans nie van 'n lydensprobleem nie. Wel kom by ons, terwyl ons lees, 'n vraag op. Hierdie vraag: Mog God dit gedoen het? Mog God ter wille van die insinuasies van die satan Job soveel laat ly? Doen God Job nie onreg nie? Te meer vra ons dit omdat Job nie 'n verklaring van God se doen en late kry nie. Maar ook vir ons, wat agter die skerms gekyk het en die rede weet, is dit 'n vraag. 
Wat tog het gebeur! Job is 'n man vroom en opreg en godvresend en een wat afgewyk het van die kwaad. Die skrywer van die boek deel dit mee (1: 1) en God self verklaar dit ook, twee keer $(1: 8 ; 2: 3)$. Dit klink asof God bly is om dit te kan konstateer. Hy verheug Hom in die vroomheid van sy kneg Job. In die aanduiding ,my kneg" lè uitgedruk dat Job God dien en dat God die diens van hom ook wil hê. Dis die verhouding tussen God en Job. Maar die satan wil daardie vreugde van God wegneem. Hy kan egter nie ontken dat Job so is nie. Hy kan geen voorbeeld noem dat Job wel gesondig het nie. Maar hy sê: Job doen dit nie verniet nie, maar omdat hy daar wel by vaar. God seën hom mos? As God egter sy hand uitstrek en alles aantas wat hy het, dan sal hy $U$ in $u$ aangesig seën.

Dis die satan wat hier 'n probleem opwerp: die probleem van die wese van die godsdiens. Hy neem die beste voorbeeld van vroomheid onder die mense wat hy kan kry (daar is niemand soos Job nie, 1: 8) en sê dan: dit gaan om die profyt, om die voordeel, om die seëninge.

Hy stel ook die alternatief: „is dit verniet dat Job God vrees?" Hy bedoel: dit sou die ware wees! En dit dink U, o God. Maar die satan stel dit problematies.

Dit gaan om die wese van die godsdiens!

En nou kom ons terug by ons vraag: mag God ter wille van die insinuasies van die satan Job so pla? Wat die satan doen is tog eintlik anders nie as problematisering van wat as vasstaande beskou word.

God weet wat Job se vroomheid is! Hy gaan egter nie met die satan diskussieer nie. Hy laat die satan die toets neem!

Mog God dit doen?

Nou beland ons midde in die probleme-maar dis nie lydensprobleme nie. Dis probleme betreffende die wese van die godsdiens en die reg van God!

Op die vraag of God dit mog doen kry ons antwoord uit Job se eie woorde: „J:" sê hy. Want nakend het hy in die wêreld gekom en nakend sal hy daar weer uitgaan. By sy bestaan behoort geen besittings nie. Wat God gee is toegif. Dit staan God vry om veel te gee of weinig te gee of niks te gee nie of alles af te neem. Hoe God ook doen, altyd moet Hy geprys word.

God mog dus alles van Job afgeneem het. Dit sê hy self. En waarom? Miskien omdat Job gesondig het? Nee! Laat ons luister nie net na wat Job sê nie, maar ook opmerk wat hy nie sê nie. Hy 
spreek nie van sonde nie. Dit sou ons gepas het. Maar hy bely niks nie. Daar is nie ' $n$ bepaalde sonde wat hom strafwaardig maak nie, maar: God is vry om te gee en te neem. Daarom alleen mog God dit gedoen het. As God dit nie mog gedoen het nie, dan sou dit beteken dat Job, dat die vrome, ja algemeen gesien, dat die mens regte sou gehad het, wat God nie mog aantas nie. Maar daar is geen sprake van regte van die mens teenoor God nie. God hoef van sy dade geen verantwoording te doen nie. Hy hoef ook geen motiewe op te gee nie. En dit erken Job. Dit is die volle vrymag van God, sy absolute soewereiniteit. Hy het alle mag in Homself, van niemand afhanklik, deur niks gebind nie.

Wat doen Job dus as die rampe hom tref? ,Seën" hy God? Dis wat die satan beweer het dat Job sou gaan doen. „Seën". Dit is 'n eufemisme en staan vir vloek.

God seën-dit is die ergste in Job se oë wat 'n mens kan doen. En ook iets waar 'n mens gemaklik toe kan verval. Job is daarvoor baie bedug. As sy kinders feesvier reken hy met die vreeslike moontlikheid, dat hulle, nie met duidelik uitgesproke woorde nie, maar in hulle hart, God sou seën, dit is God vergeet, God loslaat. Job wil God nie loslaat nie. En hy doen dit ook nie as hy deur rampe getref word. Hy wil aan sy God verbonde bly. Dit spreek hy uit nie net deur op Hom te bly vertrou nie, maar deur Hom te prys.

Job het God leer ken as die absolute Soewerein. Dis die rede waarom hy God vrees. Nie om die voordeel nie, maar om God self, omdat $\mathrm{Hy}$ Soewerein is en daarom vererenswaardig. Hy wat waarlik God ken as Soewerein, moet Hom ook eer, aanbid. Job het in aanbidding op die grond geval! Dis die waaragtige godsdiens van Job: die erkenning en daarom die verering en aanbidding van God. As Job sê: „Die HERE het gegee, en die HERE het geneem: die Naam van die HERE sy geloof"-dan is dit diep-religieuse woorde. Dis die godsdiens: erkenning van Gods soewereiniteit, aanbidding, adorasie! Nie om die voordeel nie, maar-om God self. Die satan het "verniet" as alternatief gestel. Maar dit gaan om God self! Dis ook nie aardse goedere nie, maar alleen God wat, so het Augustinus gesê-die siel van die mens kan bevredig.

Sy lyde was dus vir Job nie 'n probleem nie. Maar dit word vir hom tot 'n probleem gemaak-deur die vriende wat hom kom troos! Hullu: sê dat sy rampe 'n gevolg van sy sonde is. As dit waar was sou 
daar ook nie 'n probleem wees nie. Maar Job is oortuig van sy onskuld en handhaaf dit. Wat moet hy nou dink van Gods handelinge met hom?

Die vriende gaan uit van die retribusie-teorie, die vergeldingsteorie: God straf die sonde met rampe. Waar rampe is is dus ook sonde. Seker is waar dat God die sonde straf. Maar die wyse vriende van Job het hiervan 'n sisteem gemaak, waaraan hulle God weer bind, sodat $\mathrm{Hv}$ sy volle vrymag verloor.

Hierdie teorie is diep gewortel in die gedagtegang van Israël. Jesus moes daarteen nog veg. Hy moet sy dissipels leer dat die Galileërs, wie se bloed Pilatus met hulle offers gemeng het, nie groter sondaars was as al die Galileërs en dat die agttien op wie die toring van Siloam geval het nie meer skuldig was as al die mense wat in Jerusalem woon. (Luk. 13: 1-5). En as Hy met sy dissipels 'n man sien wat blind was van sy geboorte af en sy dissipels vra wie nou gesondig het, hierdie man of sy ouers, dan antwoord Jesus: hy nie en sy ouers ook nie, maar die werke van God moet in hom openbaar word. Dit kan ook 'n rede wees dat mense ly! Maar dit pas nie in die retribusieteorie in nie!

Blykbaar is Job self ook gevang in die vergeldingsgedagtes, want hy disputeer met sy vriende vanuit dieselfde uitgangspunt. Tog besef hy dat daar iets fout is. Die vriende handhaaf die geregtigheid van God en dan moet Job gesondig het. Hulle offer Job op, maar dis 'n bedrieglike offerande, waarin God geen welbehae het nie. Hulle teorie noem Job kernspreuke van as (13: 1-12). Maar Job hou vol dat hy regverdig is (9:21. 13:18. 27: 1-6 ens). Dan word sy konklusie dat God onregverdig moet wees. Hy sê soms dinge wat amper godslasterlik lyk. (9:22). Maar een ding het Job nie gedoen nie: God geseën. Hy het wel sy geboortedag vervloek maar God nie. Hy het juis getrag in die vir hom onverklaarbare situasie om God vas te hou. In sy verlatenheid verlang hy na God en weet dat sy God na hom verlang (14: 15), hy soek borgskap b y God te e n God. (17: 3).

Lang duur die kwelling wat sy vriende hom aandoen. Ook dit behoort tot sy beproewing. Sal Job maar nie liewer ingee nie en sê: wat help my so 'n God, wat my onregverdiglik pla? Ek laat hom maar los! Dis waarop die satan wag. Dan sou hy triomfeer! Maar Job hou vol én dat hy onskuldig is én dat hy God weer sal ontmoet. Nie sonder God nie maar met God verwag hy die einde van sy worsteling, (31:37). 
Dis die "lydsaamheid” die „hypomonè" van Job (Jak. 5: 11). Lydsaamheid is 'n aktiewe begrip: standhou, gepaard met stryd ${ }^{12}$ ), „Standhaftigkeit" ${ }^{\prime 3}$ ).

Deur sy „troosters" het sy lyde 'n probleem vir Job geword. Aanvanklik het hy Gods soewereiniteit aanbid. In die diskussies met sy vriende begin hy vra. Tog is hy al die tyd onder die majesteit van God. God doen dit vrymagtig-,,sodat die werke van God in hom openbaar sou word".

In hierdie groot middelstuk van die boek Job kom wel die probleem van die lyde aan die orde. Maar hierdie probleem lê onder die odium van 'n verkeerde teorie. Soos die satan die wese van die godsdiens geproblematiseer het, so het die vriende die lyde tot 'n probleem gemaak-waar daar nie 'n probleem was nie. Want God bly, ook as Job vra en kla en stry en uithou, die Soewereine God. God het ook ander eienskappe. Die HERE is ook vol medelye en ontferming (Jak. 5: 11). Dan kom hy tot sy einddoel. Hy verskyn aan Job, majesteitelik, uit 'n storm. En wat is die antwoord van die HERE op Job se klagte? Gee Hy 'n oplossing van Job se probleem?

Mens-ja, 'n m en s-sou dit kan verwag. Ons het met Job meegeleef. Ons het geweet waarom dit gaan. Ons het gepopel van verlange om vir Job te sê: my broeder, hou dit uit! Die saak sit so: dit gaan nie in die eerste plek om jou nie, dit gaan om God. Want die satan het gesê dat jy God vrees om die voordeel en God het gesê: toets hom dan maar. Sorg nou dat God dit win!

So sou ons ook kan dink dat, as God eindelik Job antwoord, Hy dan vir hom sê: sien Job, my kneg, dit was so: Ek het dit gedoen, omdat die satan jou betig het van voordeel soekery en Myself van kortsigtigheid. Dałrom moes Ek jou laat toets.

Maar so 'n verskoning vir sy optrede maak God nie. Hy openbaar Hom aan Job in sy volle majesteit en vra Job om antwoorde op sy vrae. Dan lê Job die hand op die mond. Hy swyg. Hy het teen God gespreek, maar sal dit nie weer doen nie, (39: 38.)

Weer erken Job die majesteit van God. 'n Oplossing kry hy nie. Hier lê die eintlike kern van die boek Job! So het die boek begin: met die soewereiniteit van God. En daarmee eindig dit. En met die soewereiniteit van God hang saam wat die wese van die godsdiens is: a a n bidding ! Ook die blindgeborene het Jesus aanbid (Joh. 9: 38). 
Is daar dan geen probleem van die lyde van die gelowiges nie? Nie vir a a $n$ bidders nie! Sekerlik kan ons probleme skep. En die aanbidding vergeet. Trouens-ons sien deur 'n spieël in 'n raaisel! Maar in Job 1 en 2 mag ons agter die skerms kyk. Nie wat ons persoonlike probleme betref, maar wel wat betref Job. Daar sien ons dat dinge nie draai om ons nie.

Job is geslinger deur die probleem, wat sy vriende geskep het. Maar as God aan hom verskyn het dan buig hy weer voor die Majesteit van God. Hy ken God weer as Hom vir wie ons nie vrae kan stel nie, as Hom wat ons vra. Hy ken Hom dan dieper: nou het my oog U gesien.

As ons die boek Job moet tipeer, karakteriseer, indeel in die geheel van die openbaring, dan moet ons sê: dis die boek van die SOEWEREINITEIT VAN GOD. En daarom die boek wat sê die wese van die godsdiens is A A NBIDDING.

\section{J. H. KROEZE.}

(1) Geschiedenis der Godsopenbaring. Het Oude Testament door Dr. F. L. Bakker. 2de druk. Kok Kampen. 1950. bl. 149 en 150

(2) Oud-testamentische Kanoniek door Dr. G. Ch. Aalders. Kok. Kampen. 1952. bl. 302.

(3) Oud-Israëlietische Geschriften door Dr. Th. C. Vriezen. Servire. Den Haag. 1948. bl. 208.

(4) Der Aufbau des Buches Hiob van Claus Westermann. Mohr. Tübingen. 1956. bl. 3 .

(5) P. Volz, aangehaald door Westermann, a.w. bl. 2.

(6) P. Volz, aangehaald door Westermann, a.w. bl. 3.

(7) Vriezen, a.w. bl. 206

(8) Lindblom, aangehaald door Westermann, a.w. bl. 2 .

(9) De Zelfrechtvaardiging Gods door Dr. K. Sietsma. Bakker. Amsterdam. (193).

(10) Introduction to the Old Testament by Aage Bentzen. Copenhagen. 1948. vol. I. bl. 181.

(11) Fridolin Stier: Das Buch Ijjob. Hebräisch und Deutsch. Kösel-Verlag. München. passim.

(12) Cremer-Kögel: Biblisch-theologisches Wörterb. 1915, sub voce.

(13) Gerard Kittel: Theologisches Wörterbuch zum N.T. 1933 en volgende jare. sub voce. 